\title{
In search of preservation strategies for the historic cultural landscape of Karabağlar Yaylası in Muğla
}

\author{
Feray Koca*(i)
}

\begin{abstract}
Historic cultural landscapes consist of pattern of layers reflecting mutual interaction of the local people with the land through time. They have material and immaterial traces of collective practices of the initial inhabitants and a local culture. Traditional determinist approach has a tendency to split material and immaterial, natural and cultural values and evaluate them separately. However, the concept of cultural landscape has been arisen as a criticism against this duality and distinction and thereafter landscapes started to be regarded as cultural representations that are shaped by both natural and cultural values. This article explores the historic cultural landscape of Karabağlar Yaylası in a rural-urban continuum in search of preservation strategies regarding changing relations with modernization and urbanization. Karabağlar Yaylası is a semi-urban and semi-rural settlement close to Muğla city centre. The seasonal migration and socio-economical interdependency have been two significant facts that sustain the settlement. However, the historic cultural landscape of Karabağlar is under threat of urban sprawl and increasing development pressures with urbanization. Modernization tools and implementations have fragmented and transformed the distinct socio-spatial pattern of Karabağlar and destroyed its character defining features over the last five decades. In order to reveal socio-spatial transformations in Karabağlar, a survey analysis was conducted. Two similar face-toface questionnaires carried out in 2006 and 2020 are evaluated comparatively. The questionnaires have been structured over how the inhabitants of Karabağlar perceive the space, how they develop land use and the symbolic meaning they attribute to the space. Findings related to field research and the empirical results of the questionnaires are evaluated holistically and changing social, economic and environmental relations are elaborated. To combat with the problems arising due to socio-spatial transformations, the article proposes some preservation strategies that care cultural values as far as natural values, perception of residents, collective memory, sense of community and their interaction with the land. This study has a potential to set up a research agenda in terms of preservation strategies for similar geographical settings.
\end{abstract}

Keywords: cultural landscape, socio-spatial transformation, preservation, Karabağlar Yaylası,

\section{Introduction}

The traditional approach that dominated the preservation of heritage values considered cultural and natural values as two opposite concepts and evaluated each value as measurable and objective. This idea generally stemmed from the inability to integrate the cultural belonging to the human 
being with the natural belonging to the land. With the influence of the science of ecology, it has become prevalent in time that the protection of the environment will include both natural and cultural values and the definition of these values may also include the subjective dimension because of the things belong to human being.

The concept of cultural landscape was introduced, especially in the early 1990s, after international conservation organizations re-evaluated the concepts of natural and cultural heritage. With the new conservation approach, which aims at the continuity of natural and cultural patterns in continuity and integrity and which eliminates the urban-rural, natural-cultural duality; geographical areas containing unique landscape elements have begun to be considered as 'cultural landscape areas' that should be preserved.

This article aims to search preservation strategies against the deterioration of historic ruralurban cultural landscape of Karabağlar Yaylası. It is a semi-rural area of historical importance, which stands out with its unique geomorphological structure, natural and cultural landscape elements and spatial pattern, on the periphery of the city of Muğla, approximately 4-5 km from the city centre. The seasonal cyclic movement between Muğla and Karabağlar occurring for centuries that has been the remnant of transhumance culture characterizes the settlement as it creates an interdependency and interaction with the city. It both contributes to the city's economy with agricultural production and meets the recreational needs of the citizens.

Karabağlar Yaylası was formed by the society shaping nature with different practices throughout the history and witnessed different social rituals and social events. The interaction of the society with the environment has created the unique spatial pattern of the settlement. In this respect, Karabaglar keeps the cultural history of initial inhabitants and presents cultural richness. The known history of Karabaglar dates back to the 17th century when the first sedentary settlement movements started with Turcoman nomads. According to the Ottoman cadastral registers, Karabağlar took a noticeable place in the agricultural production of the city. With the seasonal migration movement, it is observed that the inhabitants of Karabağlar have been multi-spatial. Until 20th century, Karabağlar preserved its authentic character of being backyard of the city. With modernization, especially after 1950s, socio economic and technological dynamics have altered the significance of Karabaglar for town economy and social life. After 1960s, the technological developments especially in transportation have been effective in the restructuring of Karabaglar settlement pattern. The cultural landscape of Karabaglar started to transform into new residential area of the town as a result of urbanization. In the recent century, developments in the economy, technology, and transportation have changed the preferences of people that influence the lifestyle and the building practices in Karabaglar. Hence, the original character, natural and cultural qualities could not sustain their existence.

This article evaluates the cultural landscape of Karabağlar Yaylası in a rural-urban continuum therefore it sets an agenda by developing preservation strategies for settlements such as Karabağlar Yaylası by revealing the changes from the past to the present, in a perspective of changing society, changing perception and preservation approach. For this purpose, after defining the concept of cultural landscape in the rural-urban continuum, how the studies on the protection of the cultural landscape have developed is succinctly explained. The character defining features consisting of natural and cultural values of Karabağlar Yaylası are examined through the historical existence of Karabağlar. As the method of the study, two questionnaires carried out on different dates in the settlement are compared, some of the similar problems in the 14 years old period are explained, and the main values, perceptions and the preservation perspective of the residents of Karabağlar are revealed. Social, economic and environmental changes in Karabağlar are explored with the changing conditions of time and modernization process. Finally, the article discusses the preservation strategies by evaluating the historic cultural landscape of Karabağlar in combination with the perception of the society and examining the perpetuation of Karabağlar's being. 


\section{Conception of cultural landscape in rural-urban continuum and the preservation of cultural landscape}

The concept of cultural landscape was first used formally by German geographer Otto Schlüter to explain territorial areas in the early 20th century. Cultural geographers used the term to describe the visible and tangible man-made forms on the landscape. In time, the concept has spread to other social and behavioural sciences like archaeology, history, ethnology, anthropology, environmental psychology, landscape ecology and became interdisciplinary (Conzen, 2001).

Cultural landscapes can be explained as the manifestations of interaction of human being with their natural environment over space and time. Common to all the fields, the traditional approach has a tendency to highlight the contrast of 'cultural' and 'natural', 'urban' and 'rural'. By creating a dichotomy, cultural and natural landscapes, urban and rural settlements are usually conceptualized as the two opposite ends of human settlements. Nevertheless, population movements, temporary seasonal migrations and socio-economic dependencies among rural and urban settlements have weaken this widespread conception.

The concept of cultural landscape has been put forward as a criticism against the traditional approach, which tends to create a distinction in the process of assigning value to everything related to culture and nature. Criticisms were made not only on the natural and cultural distinction, but also on the nature of value. It has been suggested that natural and cultural values, which were evaluated only objectively until then, can be evaluated subjectively, as they can gain moral value with the perceptions of the observer or users. The concept of landscape ecology, which emphasizes the mutual interaction and inter-relatedness of natural and human forces, has been an important starting point in this sense. The idea that cultural landscapes, which have a complex network of relations formed as a result of the relationship between human and natural factors, form a pattern in layers has started to become widespread (Jacques, 1995). It has been determined that natural and cultural values should be evaluated in an integrity and continuum with the concept of cultural landscape. Since the settlements that contain natural and cultural values together are socio-cultural assets produced by urban and rural practices, they should be evaluated in rural-urban continuum.

Analyzing the morphology of the settlements, Kostof (1989) evaluates the natural and cultural, rural and urban dilemmas as a visual contrast. He claims this dichotomy as essentially two aspects of a single continuum. He defines rural-urban continuum as a seamless physical continuity of time and space. He emphasizes the mutual dependency between rural and urban as the continuous processes of settlement: "The traditional labor of the farmer and the husbandman, set in the plains and pleats of the land and subject to seasonal rhythms, stands in millennial juxtaposition to the affairs of the city" (Kostof, 1989, p.112-113). In brief, the dependency of rural and urban is a spatiotemporal continuous process. When this continuum is broken with technological and rational developments of urbanization, discontinuity changes the existing role and significance of settlements by alienating them from their cultural, historical, traditional, local characteristics.

Arntzen (2002) describes the cultural landscape in two categories: material and immaterial. Material cultural landscape is the physical and visible manifestation of human activities. Immaterial cultural landscape, on the other hand, although they do not have any physical and visible traces, they can have symbolic meaning due to the importance they have for the members of the culture. The cultural landscape is not static, on the contrary, it is in constant change. It includes human actions that change over time, the meaning they attribute to space, and the relationship of material and immaterial values to the place. Therefore, all cultural landscapes have associative values (Taylor, 2018). To understand this associative value system, it is necessary to view cultural landscapes as a form of representation instead of physical reality. In order to understand and record the cultural landscapes, cognitive mapping is more useful instead of physical mapping. Cultural landscape is a phenomenon that depends on experience rather than observation. Therefore, the experienced dimension has an important role for the society that creates and maintains the cultural landscape (Smith, 2010). By highlighting the human role for the organically evolved and associative 
landscapes, UNESCO (2021) defines cultural landscapes as part of our collective identity in the aspect of experience.

In the late 20th century, preservation studies started to evaluate cultural landscapes not just as a visual object, they had the awareness of interconnectedness and interdependence between human being, their social and natural environment (Taylor, 2018). The first legal document to recognize and protect the concept of cultural landscape was the World Heritage Convention signed in 1992. For the first time, the Committee decided to include the cultural landscape with three categories on the World Heritage List. According to this Convention, cultural landscapes represent "the combined works of nature and of humankind" with their distinctive geomorphological structure. This concept includes the long and intimate interaction of humanity with its natural environment (UNESCO, 2021). Cultural landscape is a kind of form of social history reflecting human values and perceptions. Preservation studies and ethic emphasized the pivotal role of landscape in people's sense of place, place meaning and values. Thus, in 2011, a special interest of UNESCO to historic cultural landscapes that have the traces of different human experiences and rituals within layers lead to recognition of the management of change and values in preservation process (Taylor, 2018).

\section{Method}

This study is based on researches in the case area of Karabağlar Yaylası over a period of 20 years. The changes are recorded in the area with cadastral maps, spatial plans, photographs, land use records and ownership. In the scope of this article, a survey analysis was conducted in Karabağlar Yaylası in order to reveal socio-spatial transformation of the settlement. Within the survey analysis, two similar face-to-face questionnaires conducted in Karabağlar Yaylası in 2006 and $2020^{1}$ were evaluated comparatively. Both questionnaires were carried out during the summer months due to traditional way of life based on seasonal migration. While in 2006, 200 respondents were chosen from the local landowners who possess minimum a parcel homogeneously from Karabağlar settlement pattern; in 2020, 150 respondents were chosen with similar features. The questionnaire of 2006 consisted of three-part questions to understand the land, the building structures in the land and the user character, and open-ended questions to understand the natural and cultural values deteriorated by the changing land use. The questionnaire of 2020 mostly consists of questions to determine the character of the users and to understand ecologic and cultural situation of the settlement and the main problems and expectations that the users have. The results obtained from the two questionnaires were examined comparatively on some similar and subsequent questions and changes in relations and expectations that were determined over 14 years old period. Thus, the socio-spatial transformation, perception of residents about the change in the landscape of the settlement and the preservation activities of the local people are evaluated with the help of the empirical data obtained from the questionnaires.

\section{Historic rural-urban cultural landscape of Karabağlar Yaylası and character defining features}

Karabağlar Yaylası is a cultural landscape area that offers a unique combination of rural and urban features and processes in a historical perspective. Since its historical formation depends on the social, economic and environmental interdependency and interrelatedness between urban and rural structures, it should be considered as a socio-spatial product of cultural and natural processes.

Karabağlar Yaylası is both a semi-rural and semi-urban settlement that is 4-5 km far from Muğla city centre. The settlement is separated from the city centre by Hamursuz Hill (Figure 1). Although Karabağlar is slightly lower in altitude (approximately $625 \mathrm{~m}$ ) than Muğla town center $(650 \mathrm{~m})$, it

${ }^{1}$ The questionnaire conducted in 2020 was carried out by Muğla Karabağlar Development and Beautification Association within the scope of the "Sustainable Use of Biodiversity and Cultural Landscape Areas in Karabağlar Yaylası" Project supported under the UNEP (United Nation Environment Programme) Global Environment Facility Small Grants Programme. 
was called 'Karabağlar Yaylası (Plateau)' by the local people. With this attribute, Karabağlar is the only plateau in Anatolia that can be reached by descending.

Karabağlar Yaylası is a cultural heritage with its natural, cultural and ecological components and its unique traditional way of life is in harmony with these components. For centuries, Karabağlar Yaylası has served as a 'yaylak' (summerplace) for the people of Muğla who migrated in the summer, a 'bağ' (vineyard) consisting of vineyards that Evliya Çelebi mentioned in the 1670s, a 'bağbahçe' (orchard) that contributes to the agricultural production of the city, and a 'sayfiye yeri' (countryside) that the urban people interact with nature. It is perhaps one of the few settlements in the world that can respond to all these different land use demands. Accordingly, Karabağlar Yaylası was registered as an urban and third-degree natural site whose cultural heritage should be protected in 1977. A conservation plan, emphasizing the regulation of secondary housing density was prepared by using traditional conservation management mechanisms and ratified by Muğla Municipality in 2003.

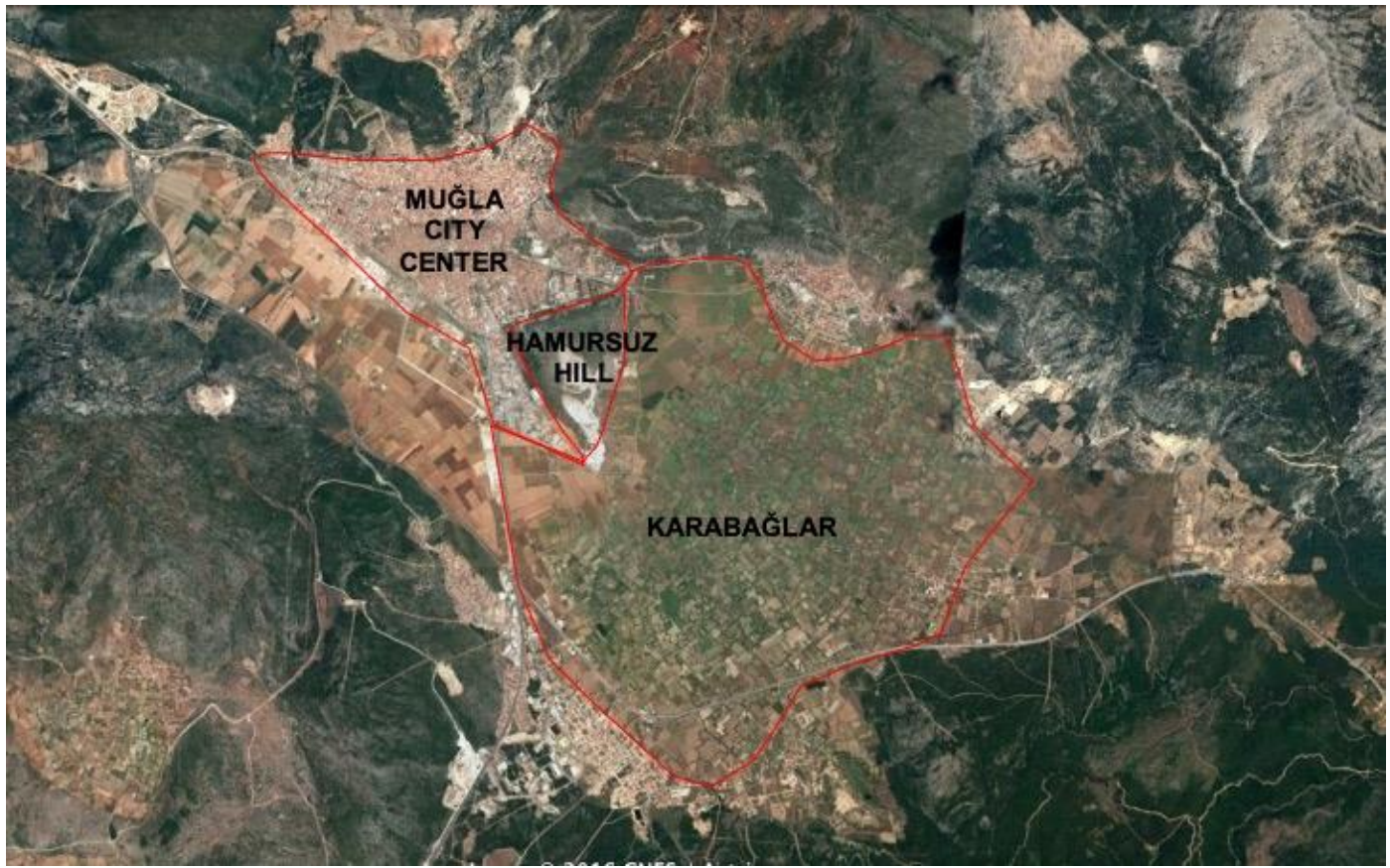

Figure 1 Location of Karabağlar Yaylası

There are some character defining features that enable Karabağlar Yaylası to be accepted as historic rural-urban cultural landscape.

\subsection{Distinctive geomorphological structure}

Karabağlar Yaylası is a depression polje (plain) with karstic-based alluvial deposits formed by tectonic movements. The main material underground consists of limestone with a porous structure, and the presence of a waterproof clay layer at a deeper level allows the formation of rich underground water. In Muğla, heavy rains in winter and spring accumulate underground thanks to the porous structure of the multi-part limestone layer and form a stable underground water source. The streams and ponding areas in the polje, which has a slightly sloping ground, allow alluvial soils to be collected on the polje floor, thus creating a very fertile and arable agricultural soil. There are well-like structures called as duden (sink-holes) that allow excess groundwater to drain. They prepare Karabağlar for a productive planting period every spring (Koca, 2012) (Figure 2). For this reason, heavy rainfall, the porous limestone layer that provides rich underground water, streams flowing on the surface of the polje, ponding areas and dudenler are indispensable structures for the continuity of Karabağlar Yaylası. Any intervention to this integrated structure can damage this ecological system irreversibly. 


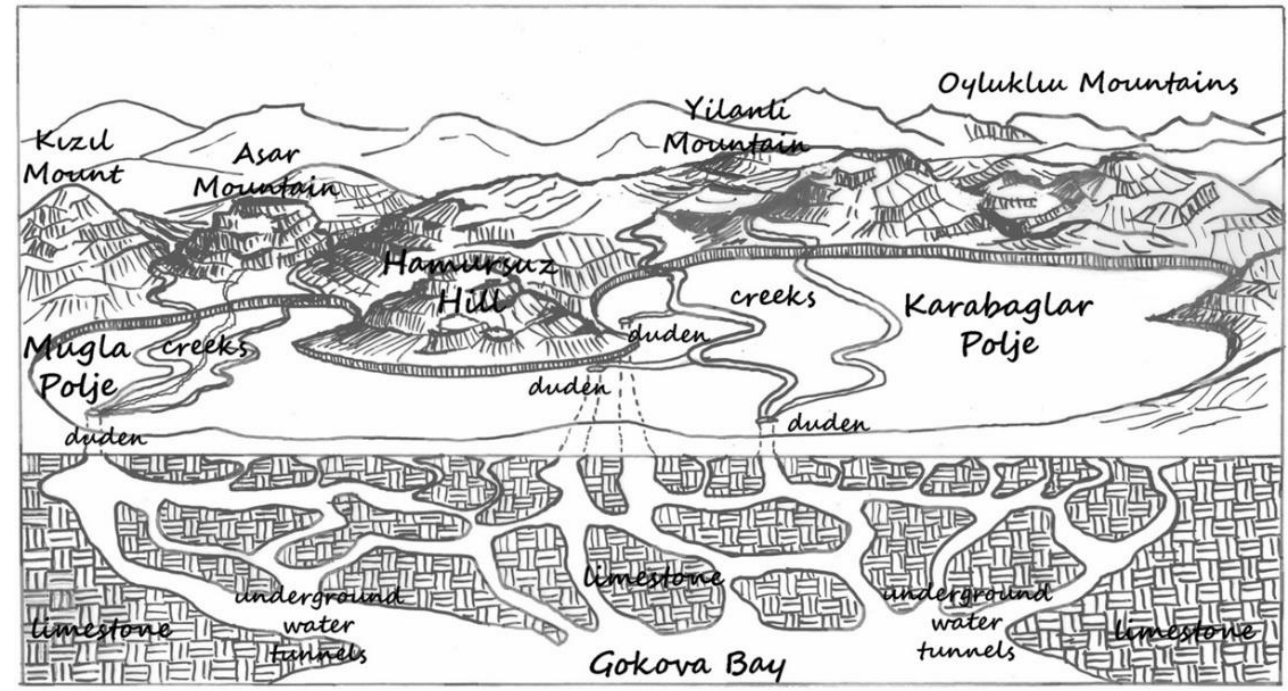

Figure 2 Geomorphological structure of Karabağlar Polje and dudenler

\subsection{Distinctive landscape components}

'Irim', 'kesik', 'kabalık' are the distinctive landscape components that shape Karabağlar. From the past to the present, these structures have been shaped by the society for social and economic purposes. In the context of the landscape element, although 'kesik' literally means 'a ditch opened around a field, vineyard, garden' in the dictionary, in Karabağlar this word refers to bushes and tree groups on the earthen elevations surrounding the fields. They are usually 1-2 m wide and 1.5-2 m high. The formation of kesikler absolutely depends on irimler. İim, which we sometimes encounter as dead end in Karabağlar, is actually a road network and creek ground created between kesikler to pass from field to field or from one parcel to another. It is generally 3 meters wide and 2 meters deep (Barlas \& Koca, 2006). In Figure 3, section of irim and kesik is given.
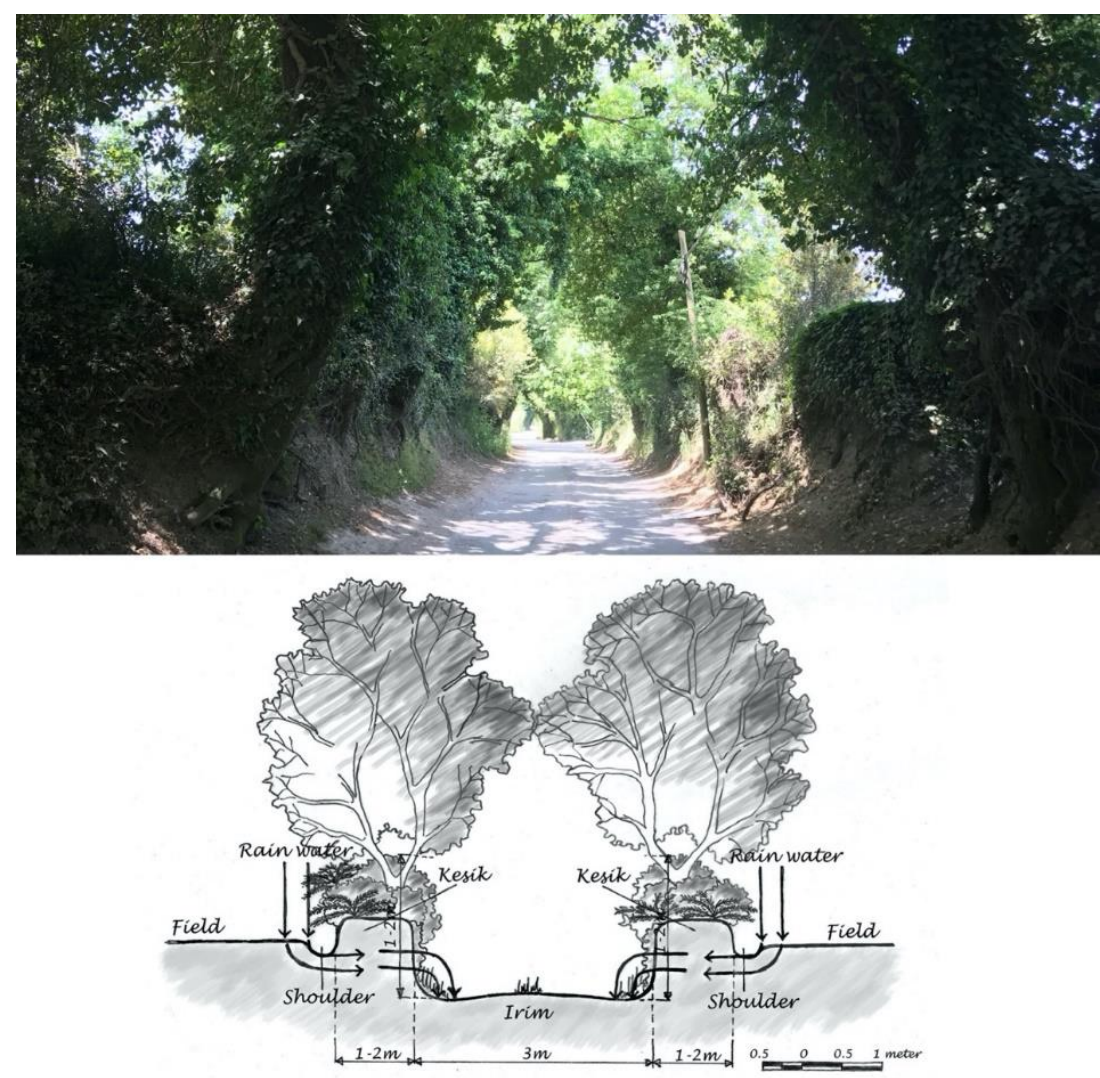

Figure 3 Section of irim and kesik 


\subsection{Biological diversity}

The presence of rich ground water and bioclimatic comfort conditions in Karabağlar offers an incredible biological diversity. The kesikler contain many kinds of wild fruits and shrubs such as rosehips, blackberries, grape vines, elms, wild pears, quince, walnuts, figs, plums, cranberries, hawthorn, oak, vines and chinchillas. The strong vegetation that grows on the kesikler creates a living and breeding area for fauna (Koca, 2012). Ensuring the continuity of the kesikler without interruption provides circulation and freedom for the fauna on it. Therefore, preventing the kesikler from being transform into wire fences or walls is crucial for the survival of the fauna.

\subsection{Distinctive socio-spatial pattern}

Social life in Karabağlar begins in the 'yurt', which constitute the smallest unit of the settlement. Although the meaning of the word 'yurt' describes the tent in a circular form used by nomadic Turkmen communities (Sözen \& Eruzun, 1992), it has also begun to express meanings such as the place settled, homeland, and motherland over time. In Karabağlar, the land consisting of a field (vineyard-garden), residence and a well is called as 'yurt' (Figure 4). Although different in size, yurtlar have similar spatial components such as residence, sofa, field, well, outbuilding, barn, courtyard, irrigation pool, fireplace, wooden bedstead, fruit trees and flower beds. Karabağlar has approximately 2890 agricultural plots with an average size of $3000-5000 \mathrm{~m} 2$ clustered under 48 locations (Koca, 2012) (Figure 5). The word 'yurt' in Karabağlar contains both existential and conceptual meanings as a product of a social understanding that sees land and home as inseparable entities. Each yurt has become a part of social life in every sense beyond being just an agricultural land. The fact that the owners of the yurtlar are called by their nickname or surname is the proof of this situation (Koca \& Barlas, 2014). In Karabağlar, yurtlar are located around the focal points where service structures such as summer coffee houses, summer masjids, grocery, bakery, shoemaker, barber, tailor etc. The focal points, which are usually referred to by the coffee name or the name of their owners, serve the yurtlar around them and form the clusters together with the yurtlar. These focal points, which are the product of private property, became a common gathering area for the local people and functioned like public squares.

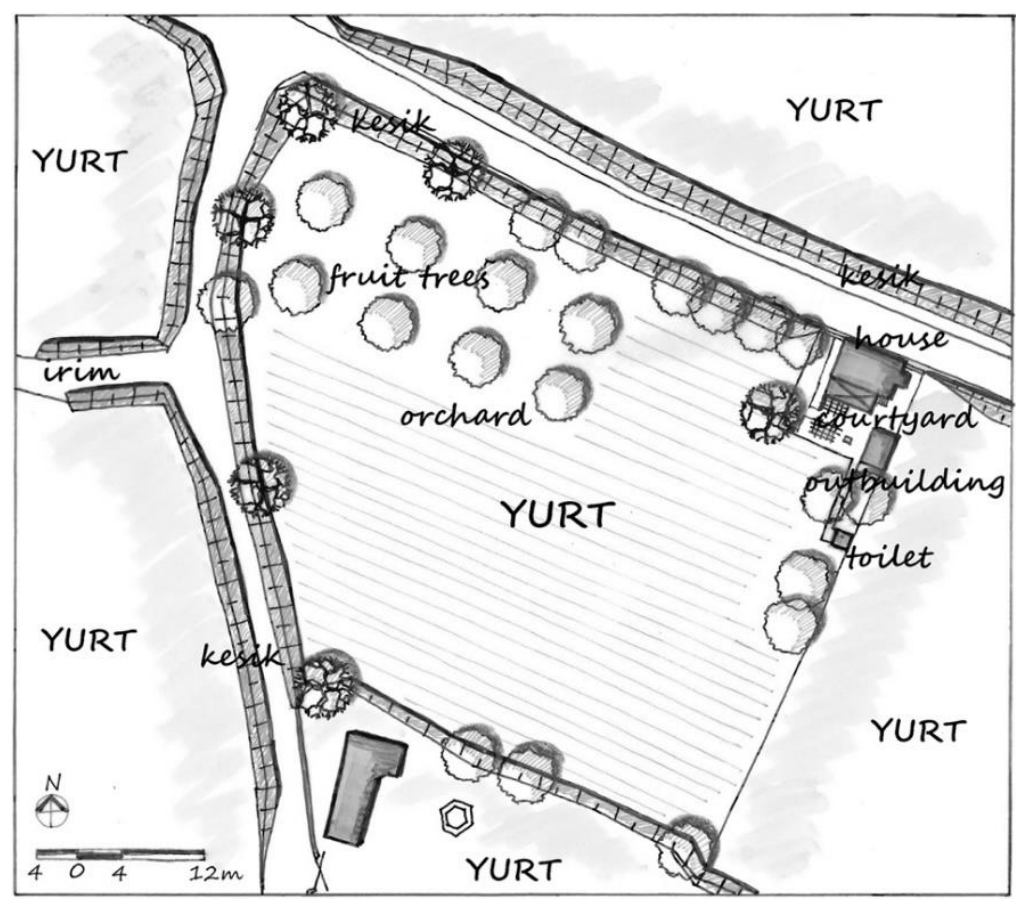

Figure 4 Plan of a 'yurt' 


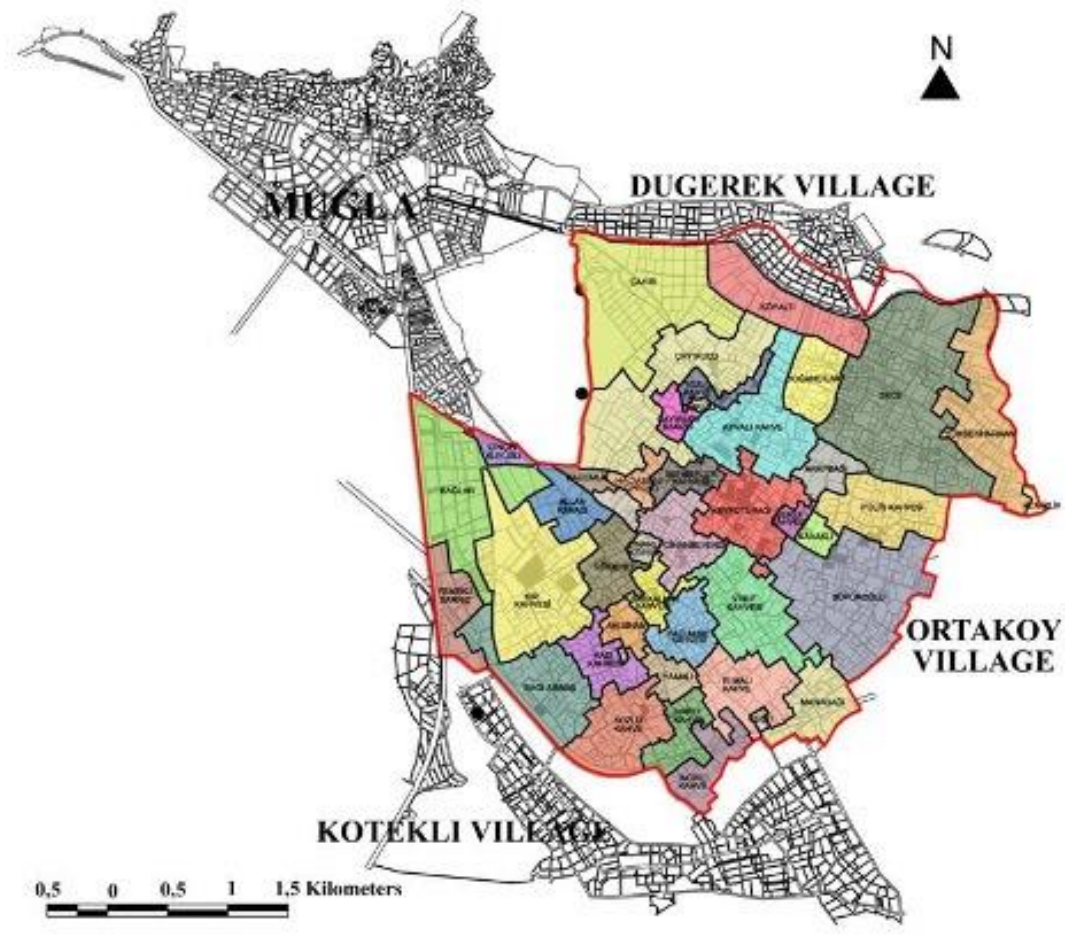

Page | 334

Figure 5 Karabağlar and its 48 locations.

\subsection{Traditional way of life based on seasonal migration}

Traditional way of life in Karabağlar is based on the seasonal migration between city center and the plain, which takes place between May and October every year. This seasonal migration-based displacement has been a necessity for the continuation of life in the past. Those who migrated to Karabağlar are not only local people, but also the craftsmen who offer services to clusters. This seasonal cycle makes the life in Karabağlar an extension of the city. Seasonal migration is obligatory because natural conditions such as ponding areas in Karabağlar formed as a result of the rains after October and the flooded road network and irimler make it impossible to stay there (Koca, 2012).

\section{Results of comparative questionnaire analysis}

Since landscape is a cultural structure that reflects human values, it is necessary to adress intangible values that creates social history in landscape studies. The intangible components of cultural landscapes that refer to historic, social and spiritual values and cultural responsibilities are the perceptions of the local inhabitants and their interaction with the natural environment (Taylor, 2016). For this reason, in this study, questionnaires were conducted in order to reveal the perspective of the people living in Karabağlar towards perceiving and using the space and giving meaning to it. Although the questionnaire conducted in 2020 is similar to the questionnaire conducted by the author in 2006, new questions were added in 2020 to address the main problems identified with the results of questionnaire of 2006.

The demographic structure of the respondents gives us information about the local users in Karabağlar Yaylası (Table 1). According to this table, the age groups of 50-59 constitute the majority of the residents in 2006, the age groups of 56-66 in 2020. It has been observed that the middleaged and older group over 50 years of age generally resides in Karabağlar and the majority of the users still adopt the seasonal migration-based traditional lifestyle. In terms of gender characteristics, it is observed that the ratio of men and women is almost close to each other. The reason for this is that the users who sustain their traditional lifestyle in Karabağlar consist of mainly couples. When we look at the birthplaces of the respondents, it is observed that most of them were born in the city center of Muğla, while the rate of users coming from different provinces was $15.7 \%$ 
in 2006 , the ratio increased to $27.9 \%$ in 2020 . The fact that Muğla has been a metropolitan city in a 14 years old period, has received immigrants from different provinces and the accessibility and recognition level of the settlements has increased from local to country-wide. In terms of educational background, the majority of respondents graduated from an elementary school in both questionnaires. It has been observed that the number of high school and university graduates has increased in 2020. This increase can be associated with the increase in educational opportunities in the 14 years old period. When we regard occupational information, in 2006, the housewives and professions with a certain area of expertise including retirees, respectively, had a high percent (27.1\% and $27.3 \%)$ among other respondents, while in 2020 , the rate of housewives $(26 \%)$ and professions with a certain area of expertise (26\%) have the highest rates. The rate of farmers has increased in 2020. When occupations are associated with age, it has been determined that the age group of 50-60 is generally composed of retired people, housewives are in the age group of 60-70, and farmers are in the age group of 40-60. When occupations are associated with education; farmers, self-employed people, workers, retired people and housewives have an educational background of elementary school in general. According to demographic results, Karabağlar households are mostly two person families composed of retired couples with an age range of 5070.

Table 1 Frequencies table related to demographical information of landowners

\begin{tabular}{|c|c|c|c|c|}
\hline \multicolumn{2}{|l|}{ LANDOWNER } & Percent (\%) & & Percent (\%) \\
\hline \multicolumn{2}{|c|}{ YEARS OF QUESTIONNAIRE } & 2006 & & 2020 \\
\hline \multirow{9}{*}{ AGE } & $0-9$ & 4,8 & $18-25$ & 10,7 \\
\hline & $10-19$ & 11 & $26-35$ & 4,0 \\
\hline & $20-29$ & 13,3 & $36-45$ & 5,3 \\
\hline & $30-39$ & 7,3 & $46-55$ & 29,3 \\
\hline & $40-49$ & 12,4 & $56-65$ & 36,7 \\
\hline & 50-59 & 21,1 & $66+$ & 14,0 \\
\hline & $60-69$ & 20 & & \\
\hline & $70-79$ & 7,6 & & \\
\hline & $80-90$ & 2,5 & & \\
\hline \multirow[t]{2}{*}{ GENDER } & man & 47,3 & \multicolumn{2}{|r|}{54,0} \\
\hline & woman & 52,7 & \multicolumn{2}{|r|}{46,0} \\
\hline \multirow{3}{*}{ PLACE OF BIRTH } & Muğla city center & 50,6 & \multicolumn{2}{|r|}{66,7} \\
\hline & towns of Muğla & 33,7 & \multicolumn{2}{|r|}{5,4} \\
\hline & different provinces & 15,7 & \multicolumn{2}{|r|}{27,9} \\
\hline \multirow{5}{*}{ EDUCATION } & illiterate & 3 & \multicolumn{2}{|r|}{-} \\
\hline & before elementary school & 3 & \multicolumn{2}{|r|}{-} \\
\hline & elementary school & 55,4 & \multicolumn{2}{|r|}{48} \\
\hline & high school & 25 & \multicolumn{2}{|r|}{38} \\
\hline & university & 13,6 & \multicolumn{2}{|r|}{14} \\
\hline \multirow{8}{*}{ OCCUPATION } & farmer & 8,4 & \multicolumn{2}{|r|}{15,3} \\
\hline & student & 15,2 & \multicolumn{2}{|r|}{8,7} \\
\hline & self-employment & 7,6 & \multicolumn{2}{|r|}{8,1} \\
\hline & worker & 6,3 & \multicolumn{2}{|r|}{7,3} \\
\hline & officer & 3,3 & \multicolumn{2}{|r|}{7,3} \\
\hline & $\begin{array}{l}\text { Professions (retired, bank } \\
\text { employee, teacher, engineer, } \\
\text { architect, lawyer, doctor, etc. }\end{array}$ & 27,3 & \multicolumn{2}{|r|}{26} \\
\hline & housewives & 27,1 & \multicolumn{2}{|r|}{26} \\
\hline & others & 4,8 & \multicolumn{2}{|r|}{1,3} \\
\hline \multirow{2}{*}{ INHABITANCY STATUS } & always & 22 & \multicolumn{2}{|r|}{27,3} \\
\hline & seasonal & 78 & \multicolumn{2}{|r|}{72,7} \\
\hline TOTAL & & $100 \%$ & \multicolumn{2}{|r|}{$100 \%$} \\
\hline
\end{tabular}


The socio-spatial existence of Karabağlar depends on seasonal migration that occurs every year between Karabağlar and Muğla city center. Geomorphological constraints of the region have made seasonal relocation as a necessity for centuries. However, developments in transportation technology, changing needs according to changing social and economic conditions with urbanization, recreational expectations prioritized over economic imperatives have depleted the seasonal dependency and mutual interaction between the two settlements over time. In terms of inhabitancy status, most of the respondents in the questionnaires still reside seasonally. The seasonal inhabitants are composed of traditional users, part-time farmers and hobby farmers. Today, with the development of transportation system, many town residents can reach Karabağlar at any time in any season. The permanent users originally consist of village migrants who choose Karabağlar because of its closeness to urban services and some migrants from different provinces who do not know the significance of seasonal migration. Thanks to floods and ponding areas in winter, many inhabitants still prefer to reside in Karabağlar only in summer.

Respondents were asked that why they choose Karabağlar to reside and answers listed in Table 2 reveal the meaning of the settlement for the respondents. $26.8 \%$ of the respondents in 2006 found cool micro-climate important. Respectively, hobby farming and resting, natural setting and healthy life, calmness were found to be important. In 2020, more than $40 \%$ of respondents stated that they are accommodating due to calmness. The distinctive geomorphological structure of Karabağlar and dense vegetation create a cool climate. However, the effects of climate change have started to be felt in Karabağlar in recent years. The cool climate feature of Karabağlar Yaylası deteriorated due to reasons such as temperature changes and decrease in annual precipitation rates, decrease in groundwater and unfair water distribution with uncontrolled wells. However, when we compare Karabağlar with Muğla city center, the scattered and low-density settlement pattern creates a calm environment, and it is a reason for the preference for rest. In general, the survey results show that preferences for recreational purposes outweigh preferences for economic purposes.

Table 2 Answers to the question: Why do you choose Karabağlar?

\begin{tabular}{|l|c|c|}
\hline OUESTION: & Percent (\%) & Percent (\%) \\
\hline Why do you choose Karabağlar? & Year 2006 & Year \\
\hline Economic contribution & 12,7 & 16,7 \\
\hline Cool climate & 26,8 & 12,7 \\
\hline Natural setting, healthy life & 13,3 & - \\
\hline Tradition & 10,9 & - \\
\hline Hobby farming and resting & 15,9 & 1,3 \\
\hline $\begin{array}{l}\text { Closeness to town (for children' school, other urban service } \\
\text { sectors) }\end{array}$ & 7,4 & 43,3 \\
\hline Calmness & 11,8 & - \\
\hline Investment & 1,2 & 16 \\
\hline All & - & 10 \\
\hline No answer & - & $100 \%$ \\
\hline TOTAL & $100 \%$ & \\
\hline
\end{tabular}

Respondents were asked if they know the functions of two distinctive landscape elements, 'irim' and 'kesik' in Karabağlar (Table 3). A great majority of the respondents in both questionnaires have a consciousness for these two components. However, in 2020, the rate of awareness is gradually decreasing. This may be due to the fact that people who moved to this settlement from different provinces have not yet learned the value of local landscape formations. 
Table 3 Answers to the question: Dou you know the functions of 'irim' and 'kesik'?

\begin{tabular}{|l|c|l|c|l|c|}
\hline OUESTION: & $\begin{array}{l}\text { Percent } \\
(\%)\end{array}$ & OUESTION & $\begin{array}{l}\text { Percent } \\
(\%)\end{array}$ & OUESTION & $\begin{array}{l}\text { Percent } \\
\text { (\%) }\end{array}$ \\
\hline $\begin{array}{l}\text { Dou you know the functions } \\
\text { of 'irim' and 'kesik'? }\end{array}$ & Year 2006 & $\begin{array}{l}\text { Dou you know the } \\
\text { functions of 'irim'? }\end{array}$ & Year 2020 & $\begin{array}{l}\text { Dou you know the } \\
\text { functions of 'kesik'? }\end{array}$ & Year 2020 \\
\hline Yes, he or she knows & 82 & Yes, he or she knows & 74,7 & Yes, he or she knows & 78,6 \\
\hline $\begin{array}{l}\text { No, he or she does not know } \\
\text { or know just one }\end{array}$ & 18 & $\begin{array}{l}\text { No, he or she does not } \\
\text { know or know just one }\end{array}$ & 25,3 & $\begin{array}{l}\text { No, he or she does not } \\
\text { know or know just one }\end{array}$ & 21,4 \\
\hline TOTAL & $100 \%$ & TOTAL & $100 \%$ & TOTAL & $100 \%$ \\
\hline
\end{tabular}

When perceived changes from past to present were asked to the respondents in 2006, different answers each of which defining the main problems experienced in Karabağlar are listed in Table 4. Technological developments (electricity, transportation, vehicles, communication, and hydrological system for wells), construction of showy modern houses, destroyed natural environment and degraded vegetation were the main transformations mentioned by the respondents. In 2020, according to these main perceived changes, respondents were asked if they accept some of these changes as problem or not (Table 5). Respondents identified destroyed irimler and kesikler and their transformation into walls and wire fences as the main problems. In addition, they stated that those who destroyed irimler and kesikler were the newcomers accommodated in the settlement for the purpose of summer residence. Some respondents have identified the destruction of the natural environment and the degradation of vegetation as a problem. While some of the respondents accept that the electricity pylons, which were accepted as one of the infrastructural changes in Karabağlar Yaylası in 2006, harm the natural environment, the majority of the respondents do not see it as a significant problem. The reason of this attitude is awareness of them about the requirement of the electricity for the area and running electricity pylons underground may cause further damage to the natural environment. Some users stated that the existence of flooding and ponding areas, which cover significant part of Karabağlar lands in winter, was considered as a problem, while a large number of users stated that it was not a problem. It is considered that users who stated that there was no problem are aware of the necessity of ponding areas for abundant groundwater. Respondents thinks that the site status of the area is partially effective in terms of preservation. However, they argue that the authorized institutions fail to fulfil their duties and that the work of public institutions in the field is insufficient.

Table 4 Answers to the question: Do you think Karabağlar have changed from past to present? What kind of changes happened?

\begin{tabular}{|c|c|}
\hline OUESTION & Percent (\%) \\
\hline Do you think Karabağlar have changed from past to present? What kind of changes happened? & Year 2006 \\
\hline Natural environment is destroyed, vegetation is degraded (elm trees) & 11 \\
\hline Kesikler and irimler are destroyed. Stonewalls and wire fences are constructed. & 4,8 \\
\hline New modern house buildings are constructed. & 12,5 \\
\hline Roads are widened and heightened, made asphalt and buses are on service & 9,3 \\
\hline Lifestyle changed, recreational use & 8,3 \\
\hline Seasonal migration ended & 4,5 \\
\hline $\begin{array}{l}\text { Coffee houses and masjids are out of service now and coffee houses became restaurants, there is no cultural } \\
\text { activity on coffee house localities }\end{array}$ & 5,8 \\
\hline There is no change or I do not know & 6,3 \\
\hline TOTAL & $100 \%$ \\
\hline
\end{tabular}


Table 5 Perceptions of the respondents about the main problems in Karabağlar in 2020

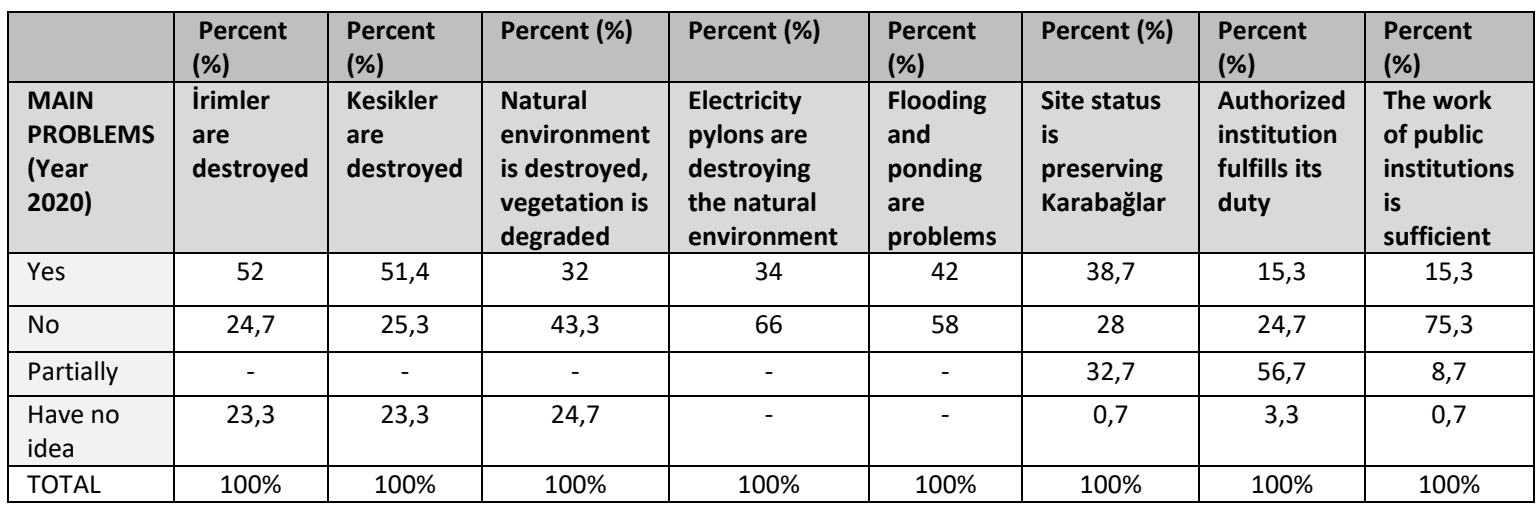

When respondents were asked how the perpetuation of Karabağlar is possible against main problems in 2006 (Figure 6), a great majority of them emphasized enhancement of infrastructure such as constructing channels to solve ponding problems, providing water supply, improving roads, reducing the number of uncontrolled artesian wells and solving garbage problems. Secondly, respondents stated that agricultural production should be supported. It is observed that the land use of newcomers in Karabağlar is principally recreational, and they mostly landscape their gardens with ornamental plants instead of agricultural plants. Some respondents are hoping for help from tourism. Some respondents stated that the residents should have consciousness about preservation practices. Others stated that the conservation plan is not sufficient, so the municipality, which is the institution responsible for the area, should take more responsibility for conservation. All these suggestions pointed to fundamental problems in Karabağlar. Respondents in the questionnaire in 2020 were expected to find solutions to the inadequacy of the conservation plan in terms of protecting the area (Figure 7). The majority of them stated that all residents in Karabağlar should be inspected in terms of the appropriateness of their practices to the conservation status of the site. Secondly, they stated that a supervisory mechanism should be developed in local-public partnership.

Table 6 Answers to the question: What does the perpetuation of Karabağlar depend on?

\begin{tabular}{|l|c|}
\hline OUESTION & Percent (\%) \\
\hline What does the perpetuation of Karabağlar depend on? & Year 2006 \\
\hline Coffee houses and masjids should be in service again & $\mathbf{7 , 6}$ \\
\hline $\begin{array}{l}\text { Infrastructure should be enhanced (canalization, water supply, ponding area problems, roads, irimler, } \\
\text { artesian wells, garbage problems) }\end{array}$ & 29,9 \\
\hline The residents should have consciousness & 7,6 \\
\hline Tourism activities should be fostered & 9,4 \\
\hline Restoration of traditional houses & 1,8 \\
\hline The natural environment should be preserved and no more house & 5,6 \\
\hline Traditional lifestyle should be fostered, people should live in Karabağlar & 5 \\
\hline No intervention is needed & 4,7 \\
\hline Agricultural production should be fostered (tobacco production and viticulture) & 13,3 \\
\hline Municipality should take care & 9 \\
\hline Site conservation plan decisions should not be applied & 6,1 \\
\hline TOTAL & $100 \%$ \\
\hline
\end{tabular}

Table 7 Answers to the question: What should be done if the conservation plan does not preserve the area?

\begin{tabular}{|l|c|}
\hline QUESTION & Percent (\%) \\
\hline $\begin{array}{l}\text { What should be done if the conservation plan does not preserve the area? (* multiple selection } \\
\text { question) }\end{array}$ & Year 2020 \\
\hline Penalties should be increased. & 16,7 \\
\hline Public scrutiny should be fostered. & 33,3 \\
\hline Residents and their practices should be inspected. & 12,0 \\
\hline A supervisory mechanism should be developed in the public-local partnership. & 25,3 \\
\hline Newcomers should be informed about Karabağlar & 1,3 \\
\hline
\end{tabular}


The participants of the questionnaire in 2020 argued that the authorized institutions, other public institutions and NGOs have not hitherto carried out adequate inspection and duty in Karabağlar Yaylası, that inspections and penalties should be increased, that they missed the former state of the settlement and that the main problems in the settlement should be resolved as soon as possible, and that a management approach that includes the demands and suggestions of the local people should be developed.

\section{Evaluation}

Karabağlar has a distinct socio-spatial pattern consisting of different layers through time, each of which refers to diverse community rituals, experiences and perceptions. Its historic cultural landscape is a result of seasonal migration and socio-economical interdependency to city centre of Muğla. Integrative analysis related to findings of field research and questionnaires is verifying that Karabağlar is transforming spatially and socially with changing socio-economic conditions. Urbanization is one of the main problems that disrupt and fragment the natural environment and wildlife habitats of the cultural landscape of settlements, besides by destroying the productive soils and agricultural production (Pauleit, Breuste, Qureshi \& Sauerwein, 2010) it is changing production relations. Threat of urban sprawl and increasing economic development pressures with urbanization have privileged modernisation implementations on historic cultural landscape of Karabağlar and led to loss of traditional communities. Accordingly, transformations in Karabağlar can be explained with three kinds of changing relations: social, economic and environmental.

Changing social relations: The traditional community, which has been carrying out agricultural production that sustain the main characteristic of farmland structure in Karabağlar for centuries, has gave way to the residents who use the land for hobby and secondary housing purposes. With the increase in mobility due to transportation technology, population growth has occurred and Karabağlar has begun to accommodate people from different backgrounds and cultures. Immigrants from nearby villages started to live in both summer and winter. Becoming a place that can be easily reached in the same day with the ease of transportation, the seasonal migration culture has been nearly diminished in Karabağlar over time. Thanks to floods and ponding areas, many people still prefer to live in summer but there is a quiet high demand for permanent inhabitancy. The changing social structure and its interaction with the land have also transformed the character defining features in time.

Changing economic relations: In Karabağlar, traditional community has carried out agricultural production based on vineyard and orchard for centuries. Viticulture and polycultural farming were the main agricultural practices in the settlement. However, the vineyard culture mentioned in Evliya Çelebi's travel book disappeared at the beginning of the 20th century with the dominance of tobacco production. After the 1950s, with the development of transportation networks and the emergence of secondary home ownership as an investment tool, traditional farming was abandoned and hobby farming started to become widespread. Yurtlar in Karabağlar regarded as an investment tool for the high-income group, and the land itself was assumed a source of economic income. The self-sufficient economy of the traditional community was replaced with the amenitybased economy of the high-income group.

Changing environmental relations: Changes in land use, increase in the number of vehicles and road network with transportation technology, increase in the number of secondary housing, abandonment of agricultural production, excessive consumption of natural resources with the overcrowding of the place, unfair sharing of water resources, insufficient water supply for agricultural irrigation in summer with the increase in the number of deep wells, structural changes, changes in the boundaries of ponding and flooding areas as a result of heightened irimler and roads, destruction of kesikler with the construction of stone walls and fences, degradation of biological diversity, deterioration of vegetation and fauna and decrease in scenic values are among the changing environmental relations. Since the integration and interrelatedness of the community 
with the environment shaped and structured the settlement; natural ecosystem, landscape pattern and character defining elements started to be corrupted with the changing society relations in the last century.

\section{Conclusion}

In Karabağlar, preservation efforts depending on conservation plan mainly excluded some cultural values and symbolic meaning of the settlements belong to human such as perception of the residents, collective memory, sense of community and their mutual interaction with the natural environment. Another important issue is that while change over time is inevitable because of the dynamic structure of the settlements, it is difficult to develop an adaptable preservation approach that will keep up with this change. Therefore, as a set of some conclusive remarks, this article proposes some preservation strategies caring the interaction of socio-economic and ecological aspects for preservation and sustainable management of historic cultural landscape of Karabağlar.

- Subjective aspects of the residents such as the sense of place, perception of values and symbolic significance should be regarded as significant facts of formation of historic cultural landscape.

- Preservation of cultural landscape should include immaterial aspects as far as material aspects such as physical setting and elements.

- Overall morphological structure and character of the settlement should be understood and respected.

- Land use character that is the reflection of the practices of initial local inhabitants should be identified and supported.

- Critical monitoring of spatial transformations and association of it with social aspects are required.

- An ecological assessment is required for the biodiversity.

- Inter- and trans-disciplinary researches and involvements in a dialogue are needed.

- A collaborative management strategy should be developed. A cooperation of public, private, academic, non-governmental organizations and the citizens should be fostered.

- Participation and involvement of the residents in the management should be provided. Perspective of the residents should be taken into account.

The rural-urban cultural landscape characteristics of Karabağlar is allowing to draw out some key issues in terms of preservation to set up a research agenda common to all similar cases. The emerging framework of this study for sustainable management that assesses both natural and cultural values co-evolved with human practices have also potentials to be adapted for other geographical settings.

\section{References}

Arntzen, S. (2002). Cultural Landscape and Approaches to Nature-Ecophilosophical Perspectives, Place and Location, 27-49.

Barlas, M. A. ve Koca, F. (2006). Introducing two landscape components from Turkey: Irim and Kesik, Landscape Research, 31:3, 215-228.

Conzen, M. P. (2001). Cultural landscape in geography, International Encyclopedia of the Social \& Behavioral Sciences, Elsevier Science Ltd., ISBN: 0-08-043076-7, 3086-3092.

Jacques, D. (1995). The rise of cultural landscapes, International Journal of Heritage Studies, 1:2, 91-101, DOI: 10.1080/13527259508722136.

Koca, F. (2012). Spatio-Temporal Transformation of 'Bağ' Settlements and Their Changing Unique Character in The Case of Muğla, Karabağlar, (Doctoral dissertation), City and Regional Planning Doctorate Program, Middle East Technical University.

Koca, F. and Barlas, M. A. (2014). Karabağlar revisited: the making of community through the yurt, the masjid, the coffeehouse, and the plane tree, Journal of Landscape Architecture, 9:1, 70-81. 
Kostof, S. (1989). Junctions of Town and Country in Bourdier, J. and Alsayyad, N. (Eds.) Dwellings, Settlements and Tradition, Cross-cultural Perspectives, International Association for The Study of Traditional Environments, Berkeley.

Pauleit, S., Breuste, J., Qureshi, S., Sauerwein, M. (2010). Transformation of rural-urban cultural landscapes in Europe: Integrating approaches from ecological, socio-economic and planning perspectives, Landscape Online, 20(1), 1-10. DOI:10.3097/LO.201020.

Smith, J. (2010). Marrying the Old with the New in Historic Urban Landscapes in World Heritage Papers 27 Managing Historic Cities, edited by Ron van Oers and Haraguchi Sachiko, 45-52. Paris: UNESCO World Heritage Centre.

Sözen, M. and Eruzun, C. (1992). Anadolu'da Ev ve Insan, (İstanbul: Creative Yayıncılık ve Dağıtım Ltd.).

Taylor, K. (2016). The Historic Urban Landscape paradigm and cities as cultural landscapes. Challenging orthodoxy in urban conservation, Landscape Research, 41:4, 471-480.

Taylor, K. (2018). Connecting Concepts of Cultural Landscape and Historic Urban Landscape: The Politics of Similarity, Built Heritage, 2, 53-67.

UNESCO (2021). https://whc.unesco.org/en/cul

\section{Resume}

Feray Koca is an Associate Professor and Vice Dean of the Faculty of Architecture at Muğla Sıtkı Koçman University, Turkey. She received her B. LArch in Landscape Architecture from Ankara University (1996-2000); her M. Sc. in Urban Design from Middle East Technical University (2001-2004) and her PhD. degree in City and Regional Planning from Middle East Technical University (2004-2012). She received her Associate Professorship in the field of City and Regional Planning (2017). She worked as a research assistant at Middle East Technical University, Department of City and Regional Planning (2004-2012). During her doctorate, she worked as a Visiting Researcher at Dortmund Technical University, Faculty of Spatial Planning (2010). She is the Head of the Department of City and Regional Planning at Muğla Sıtkı Koçman University since 2014. Her main research interests are in the areas of urban design and planning, urban morphology, landscape design, conservation of urban \& rural landscape, and urban and planning history in Turkey. 